schweben. Man filtrirt neuerdings und fügt zu dem Filtrate eine klare Mischung von Chlormagnesium, Chlorammonium und Ammonials im Ueberschuss; in der Regel ist ein Zusatz von noch etwas Chlorammoniumlösung zur Klärung der Flüssigkeit zweckmässig. Man lässt nunmehr, wie gewöhnlich, die phosphorsaure Ammon-Magnesia sich absetzen, filtrirt nach 12-24 Stunden $a b$, prüft, $o b$ sämmtliche Phosphorsäure entfernt ist und säuert dann das Filtrat mit Salzsäure an. Durch längeres Erwärmen wird sämmtliche Koblensäure entfernt und das Uranoxyd zuletzt aus der noch warmen Flüssigkeit durch Zufügen von Ammoniak bis zum schwachen Vorwalten desselben gefällt. Das Uranoxydhydrat.lässt sich leicht auswaschen, zuletzt vielleicht unter Zusatz von etwas Salmiak, und kann sofort wieder in Essigsäure gelöst werden. Man fügt in der Regel ein zu starkes Uebermaass der Magnesiamischung zu, jedoch kann die etwaige Fällung der Talkerde durch Ammoniak durch Zusatz von noch etwas Salmiak verhindert werden, wie durch die leicht zu beobachtende Vorsicht, dass kein grösseres Uebermaass von Ammoniak zur Abscheidung des Uranoxydhydrates zugefügt wird, als eben dazu nothwendig.

Gut getrocknete Uranrückstände von der Phosphorsäurebestimmung ergaben dem Verfasser bei dieser Scheidung der Phosphorsäure wiederholt die aus der annähernden Berechnung sich ergebende Menge Uranoxyd.

\title{
Als bequemstes Verfahren zur Darstellung des Kupferchlorürs
} empfiehlt Karl $\mathrm{H}$ eumann*) das folgende.

Man mische 14,2 Theile pulverisirten Kupferoxydes mit 7 Theilen gewöhnlichen Zinkstaubes sehr innig und trage das Gemenge in kleinen Portionen unter stetem Umrühren in rohe concentrirte Salzsäure ein, die sich in einem Becherglase befindet. Beim jedesmaligen Eintragen findet heftiges Zischen in Folge der energischen Reaction statt, wobei, wenn mit zu grossen Mengen gearbeitet wurde, auch Uebersprudeln der Flüssigkeit eintreten kann. Man fährt mit dem Eintragen so lange fort, bis sich ein weisser Niederschlag von Kupferchlorür zu bilden beginnt, dann fügt man neue Salzsäure zu, trägt wieder von der Mischung ein u. s. f., bis diese allmählich ganz verbraucht ist. Zuletzt giesst man, wenn sich weisses Pulver abgesclieden haben sollte, nochmals Salzsäure zu, lässt die braungelbe Flüssigkeit sich einige Augenblicke klären und giesst sie, olne den geringen aus metallischem Kupfer bestehenden Niederschlag

*, Ber. d. deutsch. chem. Ges. z. Berlin 7, 720. 
312 Bericht: Allgemeine analytische Methoden, annlytische Operationen etc.

aufzurühren, in einen Kolben, der hierauf mit ausgekochtem Wasser bis oben angefüllt und verkorkt wird.

Das Kupferchlorür scheidet sich alsbald als schneeweisses Krystallpulver aus, das, um es ganz rein zu erhalten, noch mit destillirtem Wasser gewaschen und im Dunkeln getrocknet werden muss. *)

Zur Reinigung des Quecksilbers bedient sich Albert R. Leeds**) des durch Fig. 19 dargestellten einfachen Apparates. $A$ ist ein Glas-

Fig. 19 .

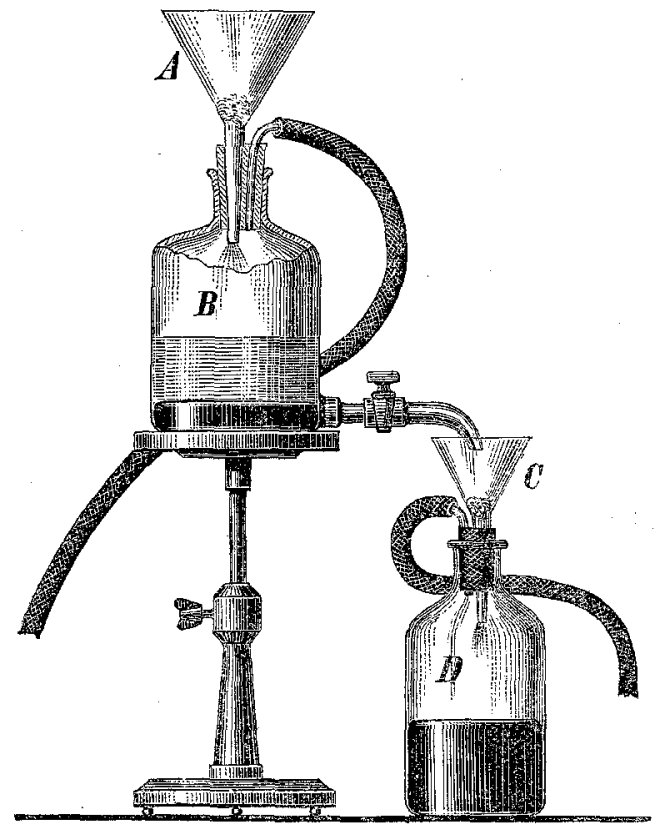
trichter, welcher $5-10$ Pfund Quecksilber fasst, sein Ablaufrohr geht durch den Stopfen der Flasche $B$ und ist dicht unter demselben abgeschnitten. Das Ablaufrohr wird mit Baumwolle gefüllt. Durch die zweite Bohrung des Stopfens geht ein kurzes, oben rechtwinklig gebogenes Rohr, welches durch einen Kautschuck schlauch mit einer Wasserluftpumpe in Verbindung steht. Die Flasche B ist zu zwei Dritttheilen mit verdünnter Salpetersäure (1 Theil Säure und 4 bis 5 Theile Wasser) gefüllt. Das in den Trichter A gegossene Quecksilber durchläuft in zahlreichen Kanälen die Baumwolle und gelangt in Gestalt eines feinen Regens in die Säure, welche die fremden Metalle auflost, während das

*) Das angegebene Mischungsverhältniss ist aus der Umsetzungsgleichung $2 \mathrm{CuO}+\mathrm{Zn}+2 \mathrm{HCl}=\mathrm{Cu}_{2} \mathrm{Cl}+\mathrm{ZnCl}+2 \mathrm{HO}$ entnommen, doch enthält das $\mathrm{Ge}-$ menge, weil auch etwas. Wasserstoffgas entwickelt wird, einen kleinen Ueberschuss an Zink, der nicht überscbritten werden darf, weil sonst das Kupferchlorür noch weiter zersetzt und auch metallisches Kupfer abgeschieden wird.

**) Am. Chemist. 4, 3є9. 